\title{
Synthesis of Inorganic Nanocomposites by Selective Introduction of Metal Complexes into a Self-Assembled Block Copolymer Template
}

\author{
Hiroaki Wakayama and Hirotaka Yonekura \\ Toyota Central ReD Laboratories, Inc., 41-1 Yokomichi, Nagakute, Aichi 480-1192, Japan \\ Correspondence should be addressed to Hiroaki Wakayama; wakayama@mosk.tytlabs.co.jp
}

Received 17 November 2014; Revised 20 March 2015; Accepted 20 March 2015

Academic Editor: Wei-Chun Chen

Copyright (C) 2015 H. Wakayama and H. Yonekura. This is an open access article distributed under the Creative Commons Attribution License, which permits unrestricted use, distribution, and reproduction in any medium, provided the original work is properly cited.

\begin{abstract}
Inorganic nanocomposites have characteristic structures that feature expanded interfaces, quantum effects, and resistance to crack propagation. These structures are promising for the improvement of many materials including thermoelectric materials, photocatalysts, and structural materials. Precise control of the inorganic nanocomposites' morphology, size, and chemical composition is very important for these applications. Here, we present a novel fabrication method to control the structures of inorganic nanocomposites by means of a self-assembled block copolymer template. Different metal complexes were selectively introduced into specific polymer blocks of the block copolymer, and subsequent removal of the block copolymer template by oxygen plasma treatment produced hexagonally packed porous structures. In contrast, calcination removal of the block copolymer template yielded nanocomposites consisting of metallic spheres in a matrix of a metal oxide. These results demonstrate that different nanostructures can be created by selective use of processes to remove the block copolymer templates. The simple process of first mixing block copolymers and magnetic nanomaterial precursors and then subsequently removing the block copolymer template enables structural control of magnetic nanomaterials, which will facilitate their applicability in patterned media, including nextgeneration perpendicular magnetic recording media.
\end{abstract}

\section{Introduction}

Inorganic nanocomposites have characteristic structures that feature expanded interfaces, quantum effects, and restrained crack propagation. These structures are promising for the improvement of many materials including thermoelectric materials [1-5], photocatalysts [6-10], and structural materials with excellent mechanical properties [11-16]. Precise control of the inorganic nanocomposites' morphology [1720], size [21-24], and chemical composition [25-27] is very important for these applications.

Templating processes that use organic materials as molds are powerful methods for controlling inorganic nanocomposites' structures [28-31]. In particular, block copolymers are fascinating templates for the control of nanostructures of inorganic nanocomposites, because the copolymers selfassemble into specific morphologies of spheres, hexagonally packed cylinders, and lamellae with periodic order typically in the range of several to several tens of nanometers [32-41].

Many studies have focused on the synthesis of inorganic nanostructures of porous materials [32-34], nanoparticles [35-37], and cylinder arrays [38] formed from block copolymer templates. In contrast, the synthesis of inorganic nanocomposites by templating block copolymers is not as well studied [39].

We recently demonstrated a synthetic route to inorganic nanocomposites by means of self-assembled block copolymer templates [40, 41]. Metal complexes are introduced into a polymer block template, and subsequent removal of the block copolymer by pyrolysis produces self-assembled 
inorganic nanocomposites of spheres, cylinders, or layers in a matrix [40]. In addition, the morphology of the block copolymer-metal complex composite can be transformed (from spheres to cylinders) by application of a magnetic field [41].

Our goal is to develop a nanofabrication process that yields controlled structures of magnetic nanomaterials and that is simpler than the processes used conventionally in the semiconductor industry. In this report, we present a novel fabrication method to control the structures of inorganic nanocomposites by means of a self-assembled block copolymer template. Metal complexes were selectively introduced into a specific polymer block of the block copolymer, and subsequent removal of the block copolymer template by oxygen plasma treatment produced hexagonally packed porous structures. In contrast, calcination removal of the block copolymer template yielded nanocomposites of metallic spheres in a matrix of a metal oxide. These results demonstrate that different nanostructures can be created by selective use of processes to remove the block copolymer templates.

\section{Experimental}

2.1. Preparation of Block Copolymer Composites. Ferrocene (bis(cyclopentadienyl) iron, >98\%, Sigma-Aldrich), acetylacetonate platinum(II) (Pt(acac) $2,99 \%$, Sigma-Aldrich), and acetylacetonate iron(III) (Fe(acac) $)_{3}, 99 \%$, Wako) were dissolved in a $0.5 \mathrm{wt} \%$ solution of polystyrene-block-poly(4vinylpyridine) (PS-P4VP, $M_{n}{ }^{\mathrm{PS}}=25.5 \mathrm{~kg} \mathrm{~mol}^{-1}, M_{n}{ }^{\mathrm{P} 4 \mathrm{VP}}=$ $24 \mathrm{~kg} \mathrm{~mol}^{-1}$, polydispersity index $=1.40$, Polymer Source) in toluene ( $>99.5 \%$, Wako). The ferrocene/styrene, Pt(acac) ${ }_{2}$ /vinylpyridine, and $\mathrm{Fe}(\mathrm{acac})_{3}$ /vinylpyridine molar ratios were 1.0/1.0, 0.5/1.0, 0.5/1.0, respectively. After stirring for $3 \mathrm{~h}$, the solution was spin-coated onto a glass substrate at $2000 \mathrm{rpm}$ from the toluene solution. After the residual solvent evaporation, the sample film was separated from the glass substrate by floating the substrate in distilled water. The sample film was transferred to a copper grid for transmission electron microscopy (TEM). For the calcination procedure, which was an alternative means to remove the block copolymer templates, the sample solution was transferred to a petri dish for the evacuation of the residual solvent.

2.2. Removal of Block Copolymer Templates. The block copolymer templates were removed by oxygen plasma treatment or by calcination in air. The sample films on the copper TEM grids were treated in oxygen plasma operating at $100 \mathrm{~W}$ for 2 or 3 min using a low-temperature plasma asher (PR300, Yamato Scientific Co., Ltd.). The sample films in petri dishes were calcined at $550^{\circ} \mathrm{C}$ for $6 \mathrm{~h}$ in flowing air.

2.3. Characterization of Block Copolymer Composites. Scanning transmission electron microscopy (STEM) and energydispersive spectroscopy (EDS) of the resulting samples were conducted with a high-resolution transmission electron microscope (JEM-2010FEF, JEOL) operating at an accelerating voltage of $200 \mathrm{keV}$. X-ray diffraction patterns were

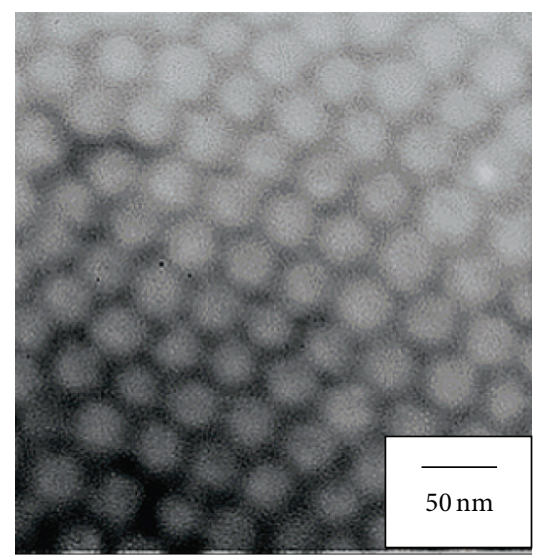

FIGURE 1: Dark-field scanning transmission electron microscopy image of a spin-coated sample prepared from PS-P4VP $(25.5 \mathrm{k} / 24 \mathrm{k})$ and three metal complexes (ferrocene, $\mathrm{Pt}(\mathrm{acac})_{2}$, and $\mathrm{Fe}(\mathrm{acac})_{3}$ ).

TABLE 1: Energy-dispersive spectroscopy results of spin-coated samples prepared from PS-P4VP $(25.5 \mathrm{k} / 24 \mathrm{k})$ and metal complexes.

\begin{tabular}{lcc}
\hline & Fe (\%) & Pt (\%) \\
\hline Sphere & 59.9 & 40.1 \\
Matrix & 93.8 & 6.2 \\
\hline
\end{tabular}

collected with $\mathrm{Cu} \mathrm{K} \alpha$ radiation on a Rigaku RINT-TTR diffractometer operated at $40 \mathrm{kV}$ and $50 \mathrm{~mA}$.

\section{Results and Discussion}

3.1. Introduction of Metal Complexes into Polymer Blocks of the Self-Assembled Block Copolymer. A STEM image of the spin-coated sample that was prepared with PS-P4VP $(25.5 \mathrm{k} / 24 \mathrm{k})$ and three metal complexes (ferrocene, $\mathrm{Pt}(\mathrm{acac})_{2}$, and $\mathrm{Fe}(\mathrm{acac})_{3}$ ) showed spherical structures (Figure 1). The formation of the spherical morphology was driven by the selective dissolution of the PS block as a matrix in toluene [42]. A dark-field STEM image of the local structure of a spincoated sample shows a spherical morphology with bright areas in the image corresponding to electron-dense spheres, suggesting that $\mathrm{Pt}(\mathrm{acac})_{2}$ was selectively introduced into the spherical P4VP block.

The EDS results in Table 1 show that Pt (40.1\%) and Fe (59.9\%) were detected in the spherical structures, whereas Fe $(93.8 \%)$ was detected in the surrounding matrix. Figure 2 shows a STEM image and an EDS map of spin-coated samples prepared from PS-P4VP $(25.5 \mathrm{k} / 24 \mathrm{k})$ and only one kind of Fe complex, $\mathrm{Fe}(\mathrm{acac})_{3}$ from toluene solution. $\mathrm{Fe}(\mathrm{acac})_{3}$ was introduced preferentially into the P4VP block. These EDS results suggest that the $\mathrm{Pt}$ complex and one of the Fe complexes were introduced into the P4VP spheres, whereas the other Fe complex was selectively introduced into the PS matrix. We reasoned that, upon dissolution in the solvent and introduction into a specific polymer block, Fe(acac) would probably behave similar to $\mathrm{Pt}(\mathrm{acac})_{2}$, which has the same organic ligand $[43,44]$, and therefore we concluded that 


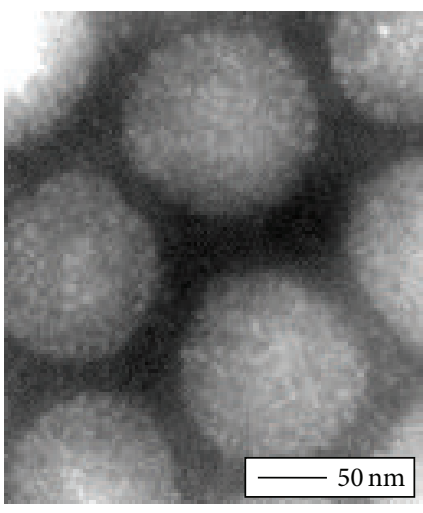

(a)

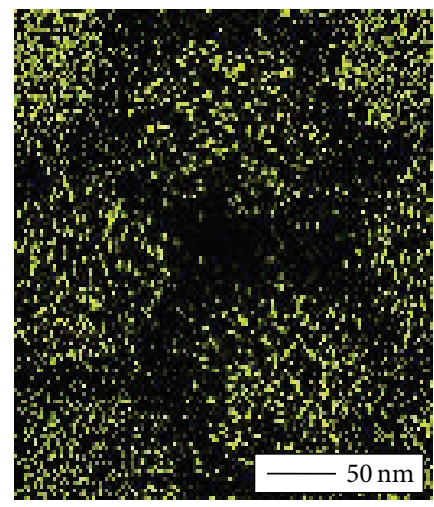

(b)

FIGURE 2: (a) Dark-field scanning transmission electron microscopy image of spin-coated samples prepared from PS-P4VP (25.5 k/24 k) and $\mathrm{Fe}(\mathrm{acac})_{3}$; (b) energy-dispersive spectroscopy mapping image for Fe (green).

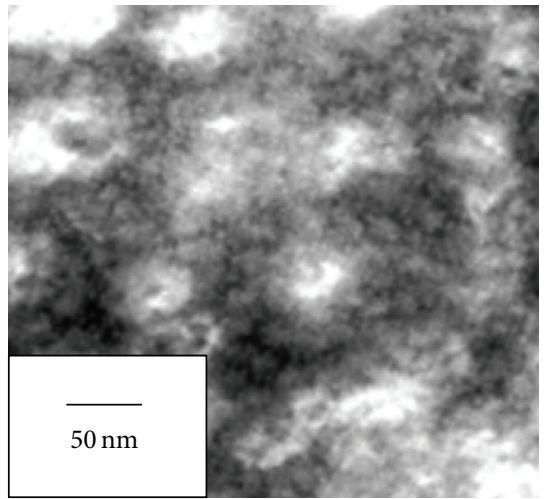

FIGURE 3: Dark-field scanning transmission electron microscopy image of a sample after treatment with oxygen plasma for $2 \mathrm{~min}$.

$\mathrm{Fe}(\mathrm{acac})_{3}$ was the Fe complex that was contained in the P4VP block.

These results indicate that the self-assembled spherical structure of P4VP enabled selective introduction of $\mathrm{Fe}(\mathrm{acac})_{3}$ and $\mathrm{Pt}(\mathrm{acac})_{2}$, whereas ferrocene was selectively introduced into the PS matrix, which was formed from selective dissolution of PS in toluene.

3.2. Oxygen Plasma Treatment for the Removal of the Block Copolymer Template. As seen in Figure 1 for the spin-coated sample, the self-assembled spheres $(30 \mathrm{~nm}$ diameter $)$ are periodically ordered in a matrix. STEM images of samples treated in oxygen plasma for 2 and $3 \mathrm{~min}$ are shown in Figures 3 and 4, respectively. The dark-field STEM image of the sample treated in oxygen plasma for 2 min shows bright spheres with diameters nearly the same as those observed in the spin-coated sample, suggesting that electron-dense $\mathrm{Pt}$ complexes are still in the spheres (Figure 3). A hexagonally packed porous structure with a bright matrix was observed in the STEM image of the sample treated in oxygen plasma for $3 \mathrm{~min}$ (Figure $4(\mathrm{a})$ ). The pore diameter is about $30 \mathrm{~nm}$, which is almost the same as the size of the spheres observed in the spin-coated sample and the sample treated in oxygen plasma for $2 \mathrm{~min}$.
TABLE 2: Energy-dispersive spectroscopy results for a calcined sample.

\begin{tabular}{lcc}
\hline & Fe (\%) & Pt (\%) \\
\hline Sphere & 38.3 & 61.7 \\
Matrix & 92.4 & 7.6 \\
\hline
\end{tabular}

The EDS mappings of Fe and Pt show that the matrix of the porous structure is composed of Fe and Pt (Figures 4(b) and $4(\mathrm{c})$ ). We concluded that the P4VP block was preferentially decomposed in oxygen plasma because the P4VP block, which is composed of pyridine rings, which contain nitrogen heteroatoms, probably was more susceptible to oxidative degradation than the PS block, which is composed of benzene rings. We presumed that as the $\mathrm{P} 4 \mathrm{VP}$ block degraded, the $\mathrm{Pt}$ and Fe species were condensed into the remaining PS matrix. These results demonstrate that oxygen plasma treatment of the block copolymer containing Fe and Pt complexes yielded porous structures of $\mathrm{Fe}$ and $\mathrm{Pt}$.

\subsection{Calcination for the Removal of the Block Copolymer} Template. In the STEM image of the sample calcined at $550^{\circ} \mathrm{C}$, bright spheres (10 $\mathrm{nm}$ in diameter) surrounded by a dark matrix are observed (Figure 5). Though shrunken in diameter, the spherical nanocomposite structures of 30 $\mathrm{nm}$ diameter that were found in the spin-coated samples were retained in the calcined sample. The brightness of the spheres in the dark-field STEM image of the calcined sample suggested that electron-dense Pt was present in the spheres. The EDS results in Table 2 show that the spheres were composed of Fe and $\mathrm{Pt}$, whereas the matrix was composed mainly of Fe.

In contrast to the results observed upon removal of the block copolymer template by calcination, in which the spherical structures remained, the spheres became pores after treatment in oxygen plasma. This difference in morphology was attributed to the difference between the PS and P4VP blocks' susceptibility to oxidation. In the calcination process, the PS and P4VP blocks decomposed within the same 


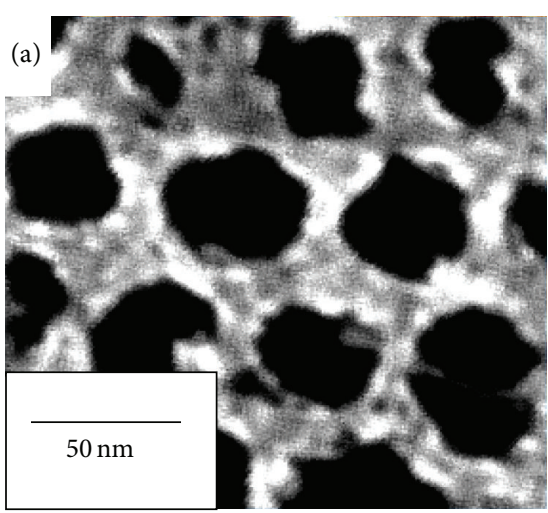

(a)

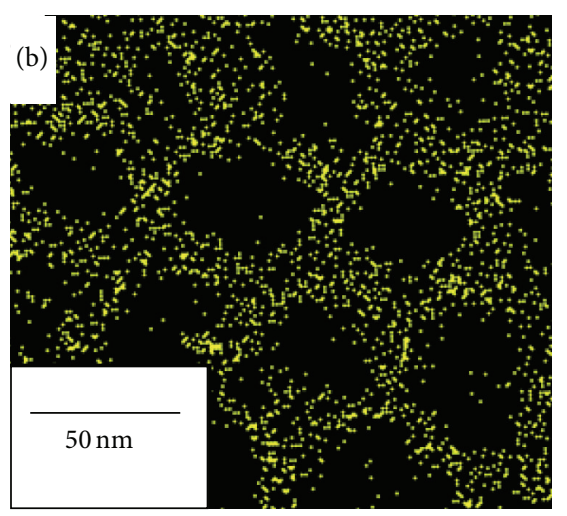

(b)

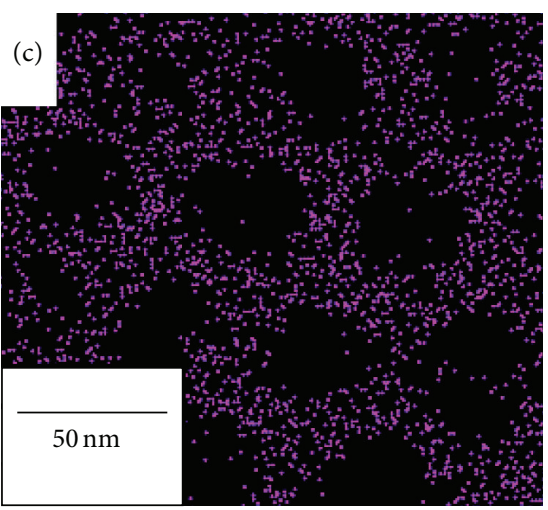

(c)

FIGURE 4: (a) Dark-field scanning transmission electron microscopy images of a sample after treatment with oxygen plasma for 3 min; energydispersive spectroscopy mapping images for (b) Fe and (c) Pt.

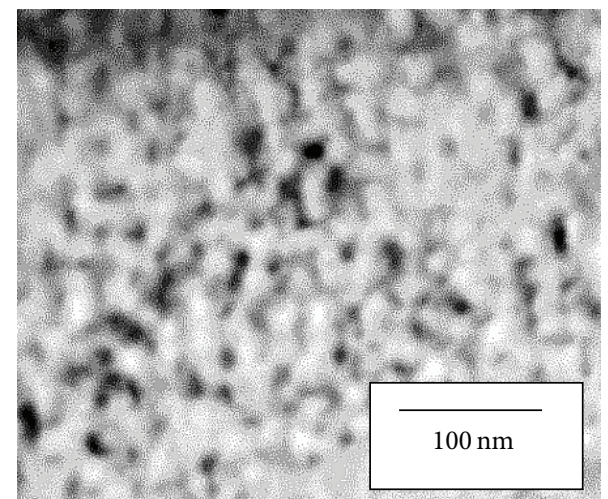

Figure 5: Dark-field scanning transmission electron microscopy image of a calcined sample.

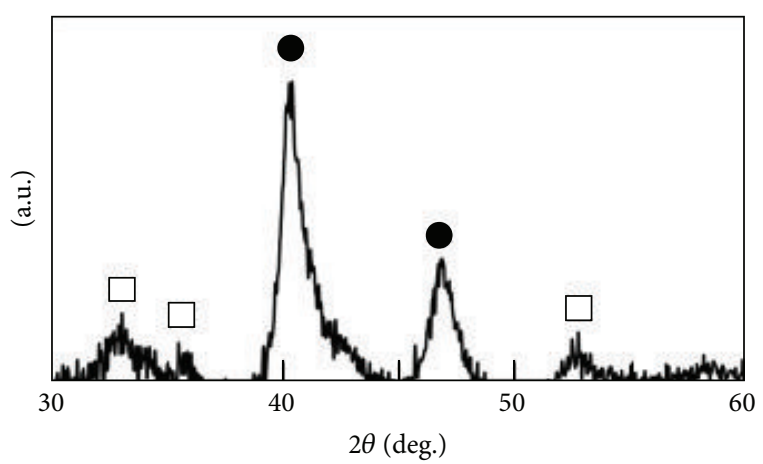

FIGURE 6: X-ray scattering profile of a calcined sample, indicating the presence of $\mathrm{FePt}$ (closed circles) and $\mathrm{Fe}_{2} \mathrm{O}_{3}$ (open squares).

temperature range of $370-460^{\circ} \mathrm{C}$ [40], and as the block copolymer template decomposed, the block copolymer-metal complex composite spheres shrank to yield Fe and Pt spheres in an Fe containing matrix.

The X-ray diffraction profile of the calcined sample confirms the existence of two crystalline phases (Figure 6). One phase was identified as the $\mathrm{Ll}_{0}$ tetragonal $\mathrm{FePt}$, and the second phase is $\mathrm{Fe}_{2} \mathrm{O}_{3}$, indicating that the calcined sample was a nanocomposite of metallic spheres in a metal oxide matrix.

\section{Conclusion}

A novel fabrication method to control the structures of inorganic nanocomposites by templating a self-assembling block copolymer is demonstrated. Metal complexes were selectively introduced into a specific polymer block, and subsequent removal of the block copolymer by oxygen plasma treatment produced hexagonally packed porous structures. In contrast, calcination removal of the block copolymer template yielded a nanocomposite of metallic spheres in a matrix of a metal oxide. We have therefore demonstrated that different nanostructures can be created by selective use of processes to remove the block copolymer template. The process demonstrated herein, consisting of simple mixing of the block copolymer and magnetic nanomaterial precursors and subsequent removal of the block copolymer template, enables the structural control of magnetic nanomaterials, which will facilitate their application in patterned media, including next-generation perpendicular magnetic recording media. This novel method to control nanostructures of inorganic nanocomposites can be applied to other chemical species, including other metals, oxides, carbides, nitrates, and sulfides. This method also is promising for the improvement of nanocomposites' properties in many applications.

\section{Conflict of Interests}

The authors declare that there is no conflict of interests regarding the publication of this paper.

\section{References}

[1] G. J. Snyder and E. S. Toberer, "Complex thermoelectric materials," Nature Materials, vol. 7, no. 2, pp. 105-114, 2008.

[2] M. S. Dresselhaus, G. Chen, M. Y. Tang et al., "New directions for low-dimensional thermoelectric materials," Advanced Materials, vol. 19, no. 8, pp. 1043-1053, 2007. 
[3] Y. Q. Cao, X. B. Zhao, T. J. Zhu, X. B. Zhang, and J. P. Tu, "Syntheses and thermoelectric properties of $\mathrm{Bi}_{2} \mathrm{Te}_{3} / \mathrm{Sb}_{2} \mathrm{Te}_{3}$ bulk nanocomposites with laminated nanostructure," Applied Physics Letters, vol. 92, Article ID 143106, 2008.

[4] J. H. Liu, H. Y. Miao, S. Lakshmanan, L.-C. Wang, and R.-H. Tsai, "Fabrication of metal alloy-deposited flexible MWCNT buckypaper for thermoelectric applications," Journal of Nanomaterials, vol. 2013, Article ID 635647, 6 pages, 2013.

[5] P. Slobodian, P. Riha, R. Olejnik, M. Kovar, and P. Svoboda, "Thermoelectric properties of carbon nanotube and nanofiber based ethylene-octene copolymer composites for thermoelectric devices," Journal of Nanomaterials, vol. 2013, Article ID 792875, 7 pages, 2013.

[6] Y. J. Wang, J. C. Liu, L. Liu, and D. D. Sun, "Enhancing stability and photocatalytic activity of $\mathrm{ZnO}$ nanoparticles by surface modification of graphene oxide," Journal of Nanoscience and Nanotechnology, vol. 12, no. 5, pp. 3896-3902, 2012.

[7] D. Yu, B. Bo, and H. Yunhua, "Fabrication of $\mathrm{TiO}_{2}$ @yeastcarbon hybrid composites with the raspberry-like structure and their synergistic adsorption-photocatalysis performance," Journal of Nanomaterials, vol. 2013, Article ID 851417, 8 pages, 2013.

[8] L. Zhang, J. Yan, M. Zhou, and Y. Liu, "Preparation, characterization, and enhanced photocatalytic hydrogen evolution activity of $\mathrm{Y}_{2} \mathrm{Cu}_{2} \mathrm{O}_{5}$-based compounds under simulated sunlight irradiation," Journal of Nanomaterials, vol. 2013, Article ID 852139, 8 pages, 2013.

[9] K. Woan, G. Pyrgiotakis, and W. Sigmund, "Photocatalytic carbon-nanotube- $\mathrm{TiO}_{2}$ composites," Advanced Materials, vol. 21, no. 21, pp. 2233-2239, 2009.

[10] H. Zhang, X. Lv, Y. Li, Y. Wang, and J. Li, "P25-graphene composite as a high performance photocatalyst," ACS Nano, vol. 4, no. 1, pp. 380-386, 2010.

[11] S. Vepřek, “The search for novel, superhard materials," Journal of Vacuum Science and Technology A: Vacuum, Surfaces and Films, vol. 17, no. 5, pp. 2401-2420, 1999.

[12] E. W. Wong, P. E. Sheehan, and C. M. Lieber, "Nanobeam mechanics: elasticity, strength, and toughness of nanorods and nanotubes," Science, vol. 277, no. 5334, pp. 1971-1975, 1997.

[13] E. Hernández, C. Goze, P. Bernier, and A. Rubio, "Elastic properties of $\mathrm{C}$ and BxCyNz composite nanotubes," Physical Review Letters, vol. 80, no. 20, pp. 4502-4505, 1998.

[14] A. B. Elshalakany, T. A. Osman, A. Khattab, B. Azzam, and M. Zaki, "Microstructure and mechanical properties of MWCNTs reinforced A356 aluminum alloys cast nanocomposites fabricated by using a combination of rheocasting and squeeze casting techniques," Journal of Nanomaterials, vol. 2014, Article ID 386370, 14 pages, 2014.

[15] J. Huang, Z. Huang, S. Zhang, M. Fang, and Y. Liu, " $\mathrm{Si}_{3} \mathrm{~N}_{4}$ $\mathrm{SiC}_{p}$ composites reinforced by in situ co-catalyzed generated $\mathrm{Si}_{3} \mathrm{~N}_{4}$ nanofibers," Journal of Nanomaterials, vol. 2014, Article ID 752378, 6 pages, 2014.

[16] F. Wang, L. F. Zhang, P. Huang, J. Y. Xie, T. J. Lu, and K. $\mathrm{W}$. $\mathrm{Xu}$, "Microstructure and flow stress of nanoscale $\mathrm{Cu} / \mathrm{Nb}$ multilayers," Journal of Nanomaterials, vol. 2013, Article ID 912548, 8 pages, 2013.

[17] C. Guerret-Piécourt, Y. le Bouar, A. Loiseau, and H. Pascard, "Relation between metal electronic structure and morphology of metal compounds inside carbon nanotubes," Nature, vol. 372, no. 6508 , pp. 761-765, 1994.
[18] S.-Y. Chang, L. Liu, and S. A. Asher, "Preparation and properties of tailored morphology, monodisperse colloidal silicacadmium sulfide nanocomposites," Journal of the American Chemical Society, vol. 116, no. 15, pp. 6739-6744, 1994.

[19] K. Matsubara and T. Tatsuma, "Morphological changes and multicolor photochromism of Ag nanoparticles deposited on single-crystalline $\mathrm{TiO}_{2}$ surfaces," Advanced Materials, vol. 19, no. 19, pp. 2802-2806, 2007.

[20] V. Ovchinnikov and A. Shevchenko, "Morphology and surface plasmon resonances of silver anocomposite layer-by-layer films," Journal of Nanoscience and Nanotechnology, vol. 9, no. 6, pp. 3872-3876, 2009.

[21] S. Das, S. K. Panda, P. Nandi, S. Chaudhuri, A. Pandey, and R. Ranganathan, "Silica encapsulated ni nanoparticles: variation of optical and magnetic properties with particle size," Journal of Nanoscience and Nanotechnology, vol. 7, no. 12, pp. 4447-4455, 2007.

[22] V. Subramanian, E. E. Wolf, and P. V. Kamat, "Catalysis with $\mathrm{TiO}_{2}$ /gold nanocomposites. effect of metal particle size on the fermi level equilibration," Journal of the American Chemical Society, vol. 126, no. 15, pp. 4943-4950, 2004.

[23] K. Yamamoto, T. Imaoka, W. J. Chun et al., "Size-specific catalytic activity of platinum clusters enhances oxygen reduction reactions," Nature Chemistry, vol. 1, no. 5, pp. 397-402, 2009.

[24] Y. Qiu, K. Yan, S. Yang, L. Jin, H. Deng, and W. Li, "Synthesis of size-tunable anatase $\mathrm{TiO}_{2}$ nanospindles and their assembly into Anatase@Titanium oxynitride/titanium nitride-graphene nanocomposites for rechargeable lithium ion batteries with high cycling performance," ACS Nano, vol. 4, no. 11, pp. 65156526, 2010.

[25] G. Ramírez, D. Oezer, M. Rivera, S. E. Rodil, and R. Sanjinés, "TaSiN nanocomposite thin films: correlation between structure, chemical composition, and physical properties," Thin Solid Films, vol. 558, pp. 104-111, 2014.

[26] D. H. Kim, N. M. Aimon, X. Sun, and C. A. Ross, "Compositionally modulated magnetic epitaxial spinel/perovskite nanocomposite thin films," Advanced Functional Materials, vol. 24, no. 16, pp. 2334-2342, 2014.

[27] Y. Xiao, Y. Cao, Y. Gong et al., "Electrolyte and composition effects on the performances of asymmetric supercapacitors constructed with $\mathrm{Mn}_{3} \mathrm{O}_{4}$ nanoparticles-graphene nanocomposites," Journal of Power Sources, vol. 246, pp. 926-933, 2014.

[28] D. K. Yi, S. S. Lee, G. C. Papaefthymiou, and J. Y. Ying, "Nanoparticle architectures templated by $\mathrm{SiO}_{2} / \mathrm{Fe}_{2} \mathrm{O}_{3}$ nanocomposites," Chemistry of Materials, vol. 18, no. 3, pp. 614-619, 2006.

[29] P. Wu, J. Zhu, and Z. Xu, “Template-assisted synthesis of mesoporous magnetic nanocomposite particles," Advanced Functional Materials, vol. 14, no. 4, pp. 345-351, 2004.

[30] Q. Jiang, Z. Y. Wu, Y. M. Wang, Y. Cao, C. F. Zhou, and J. H. $\mathrm{Zhu}$, "Fabrication of photoluminescent $\mathrm{ZnO} / \mathrm{SBA}-15$ through directly dispersing zinc nitrate into the as-prepared mesoporous silica occluded with template," Journal of Materials Chemistry, vol. 16, no. 16, pp. 1536-1542, 2006.

[31] J. Wang, S. J. Sollenberger, Y. Yuan, T. J. Yosenick, and J. H. Adair, "Silica encapsulated CdS tabular nanocomposites via a template directed agglomeration mechanism," Journal of Nanoscience and Nanotechnology, vol. 8, no. 11, pp. 5878-5886, 2008.

[32] R. A. Pai, R. Humayun, M. T. Schulberg, A. Sengupta, J.-N. Sun, and J. J. Watkins, "Mesoporous silicates prepared using preorganized templates in supercritical fluids," Science, vol. 303, no. 5657, pp. 507-510, 2004. 
[33] P. Yang, D. Zhao, D. I. Margolese, B. F. Chmelka, and G. D. Stucky, "Block copolymer templating syntheses of mesoporous metal oxides with large ordering lengths and semicrystalline framework," Chemistry of Materials, vol. 11, no. 10, pp. 28132826, 1999.

[34] S. C. Warren, L. C. Messina, L. S. Slaughter et al., "Ordered mesoporous materials from metal nanoparticle-block copolymer self-assembly," Science, vol. 320, no. 5884, pp. 1748-1752, 2008.

[35] M. Templin, A. Franck, A. Du Chesne et al., "Organically modified aluminosilicate mesostructures from block copolymer phases," Science, vol. 278, no. 5344, pp. 1795-1798, 1997.

[36] C. B. W. Garcia, Y. M. Zhang, S. Mahajan, F. DiSalvo, and U. Wiesner, "Self-assembly approach toward magnetic silica-type nanoparticles of different shapes from reverse block copolymer mesophases," Journal of the American Chemical Society, vol. 125, no. 44, pp. 13310-13311, 2003.

[37] B. K. Kuila, M. S. Rama, and M. Stamm, "Supramolecular assembly of poly(styrene)-b-poly(4-vinylpyridine) and ferroceneacetic acid: an easy way to large-scale controllable periodic arrays of iron oxide nanomaterials," Advanced Materials, vol. 23, no. 15, pp. 1797-1800, 2011.

[38] A. Chen, M. Komura, K. Kamata, and T. Iyoda, "Highly ordered arrays of mesoporous silica nanorods with tunable aspect ratios from block copolymer thin films," Advanced Materials, vol. 20, no. 4, pp. 763-767, 2008.

[39] B. H. Sohn, J. M. Choi, S. I. Yoo et al., "Directed self-assembly of two kinds of nanoparticles utilizing monolayer films of diblock copolymer micelles," Journal of the American Chemical Society, vol. 125, no. 21, pp. 6368-6369, 2003.

[40] H. Wakayama, H. Yonekura, and Y. Kawai, “Three-dimensional periodically ordered nanohetero metallic materials from selfassembled block copolymer composites," ACS Macro Letters, vol. 2, no. 4, pp. 284-287, 2013.

[41] H. Wakayama, H. Yonekura, and M. Harada, "Effects of metal loading and magnetic field strength on alignment of noncrystalline block copolymers doped with metal complexes," Journal of Polymer Research, vol. 21, p. 488, 2014.

[42] J. C. Meiners, A. Quintel-Ritzi, J. Mlynek, H. Elbs, and G. Krausch, "Adsorption of block-copolymer micelles from a selective solvent," Macromolecules, vol. 30, no. 17, pp. 4945-4951, 1997.

[43] M. Haruki, K. Kishimoto, F. Kobayashi, S.-I. Kihara, and S. Takishima, "A new correlation and prediction method for the solubility of metal complexes in supercritical carbon dioxide using regular solution theory with the COSMO-RS method," Journal of Chemical Engineering of Japan, vol. 42, no. 5, pp. 309$318,2009$.

[44] M. Haruki, F. Kobayashi, K. Kishimoto, S. I. Kihara, and S. Takishima, "Measurement of the solubility of metal complexes in supercritical carbon dioxide using a UV-vis spectrometer," Fluid Phase Equilibria, vol. 280, no. 1-2, pp. 49-55, 2009. 

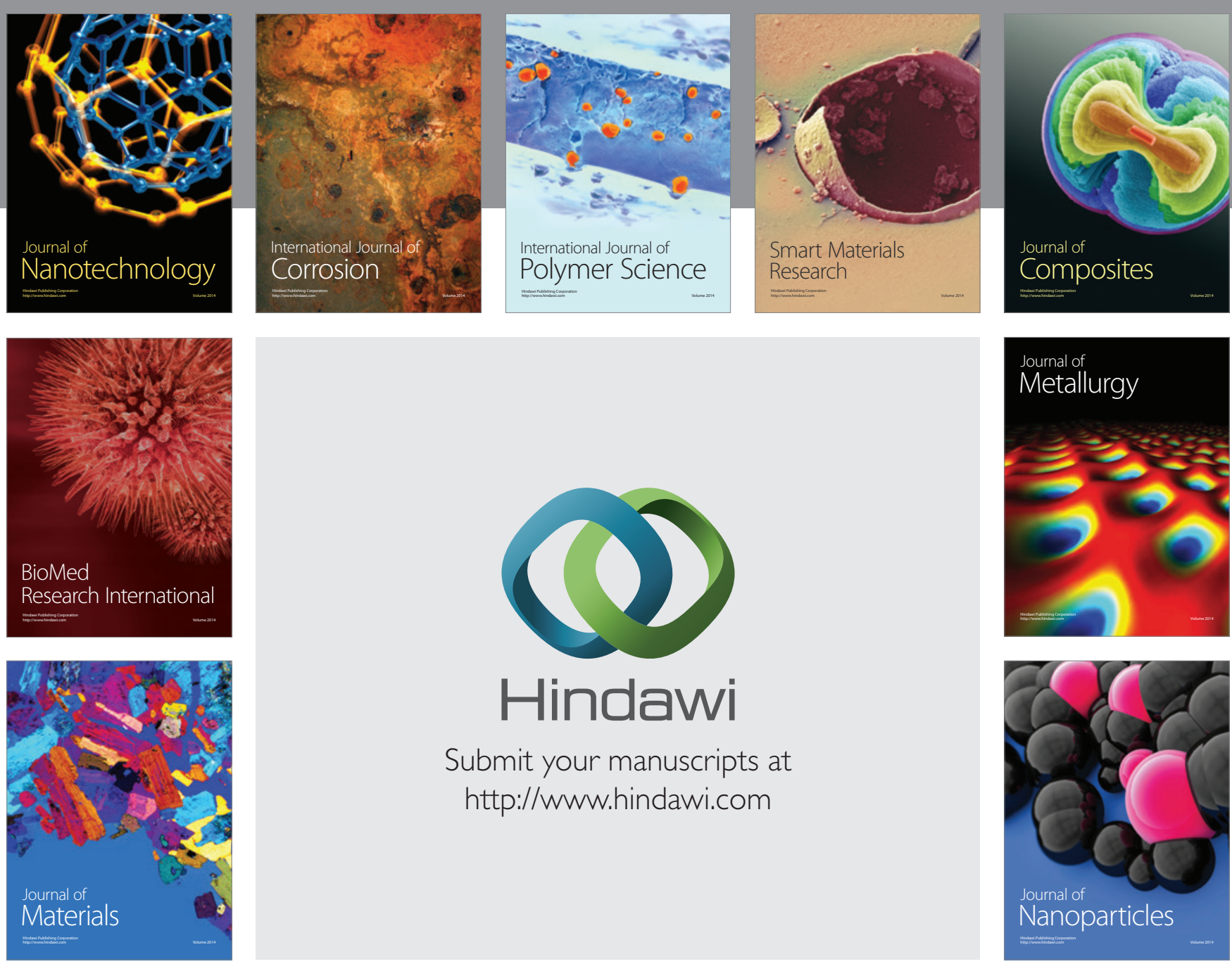

Submit your manuscripts at http://www.hindawi.com
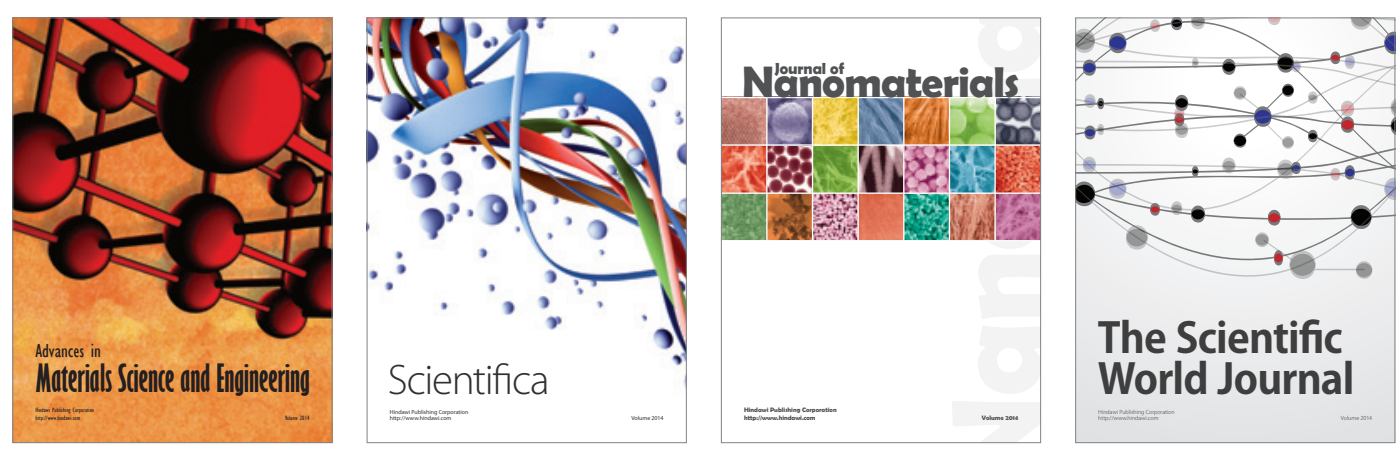

\section{The Scientific World Journal}
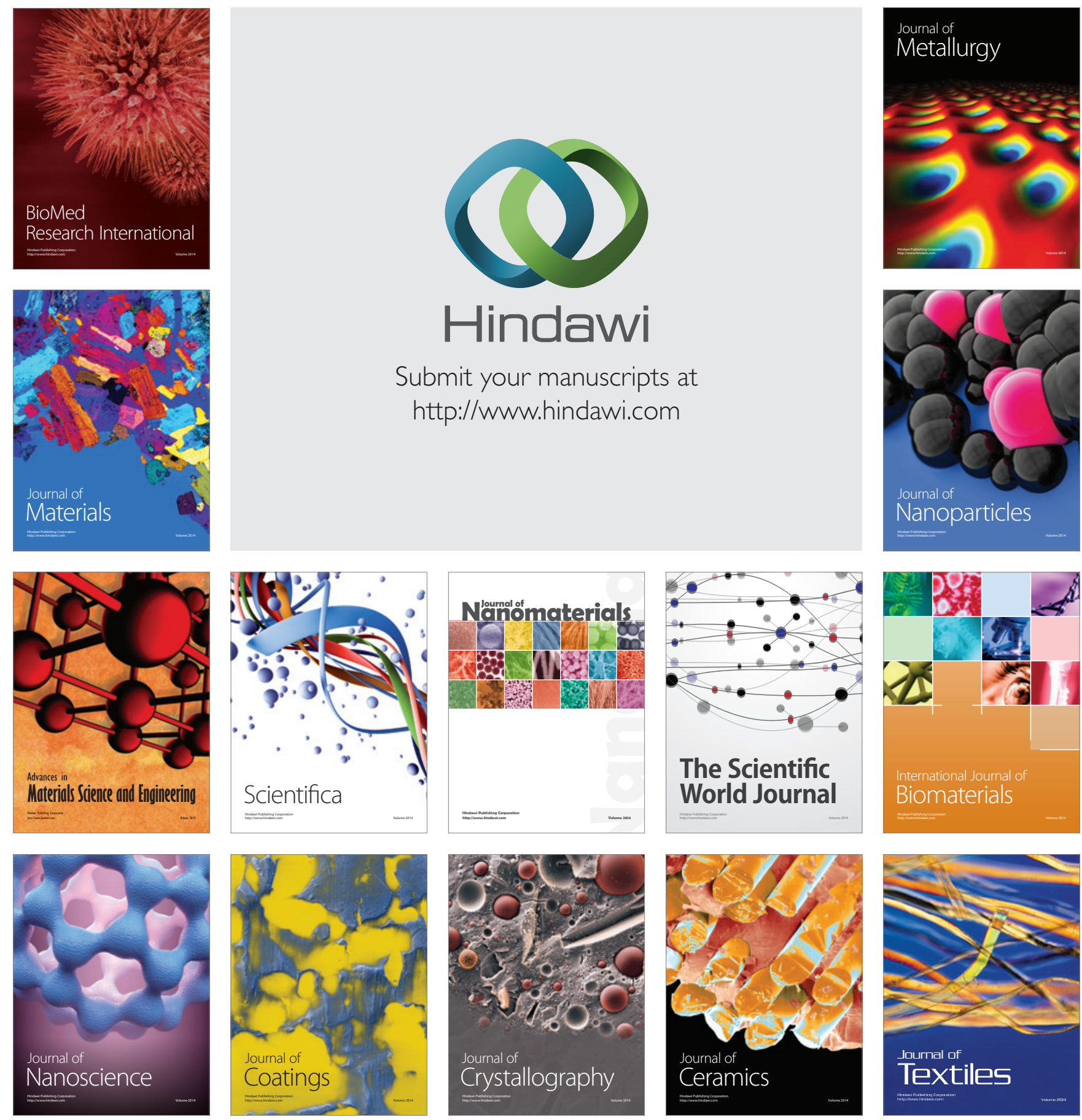